\title{
Metabolism of Heptadecapeptide Gastrin in Humans Studied by Region-specific Antisera
}

\author{
S. Pauwels, G. J. Dockray, R. Walker, and S. Marcus \\ Medical Research Council Secretory Control Research Group, Physiological Laboratory, University of Liverpool, \\ Liverpool, United Kingdom, and Gastrointestinal Unit, Walton Hospital, Liverpool, United Kingdom
}

\begin{abstract}
The metabolism of synthetic human heptadecapeptide gastrin (G17) in vivo, and in serum in vitro, was studied by radioimmunoassay using region specific antisera, gel filtration, ion exchange chromatography, and high performance liquid chromatography. After infusion of G17 intravenously in normal human volunteers, $\mathrm{COOH}$-terminal and $\mathrm{NH}_{2}$-terminal immunoreactive G17 fragments were generated. At a steady state, $\sim 15 \%$ of $\mathrm{COOH}$-terminal immunoreactivity was attributable to G14-like material and up to $25 \%$ of total $\mathrm{NH}_{2}$-terminal immunoreactivity was attributable to two $\mathrm{NH}_{2}$-terminal fragments; one had the chromatographic properties of 1-13 G17, and the other was less acidic and less hydrophobic. After stopping the infusion of G17, the latter fragments accounted for progressively greater proportions of total gastrin activity. When G17 was incubated in serum in vitro, there was timedependent and temperature-dependent loss of immunoreactivity, and again $\mathrm{COOH}$-terminal and $\mathrm{NH}_{2}$-terminal immunoreactive fragments were formed. Removal of the $\mathrm{NH}_{2}$-terminal pyroglutamic acid was probably the rate limiting step because synthetic 2-17 G17 was degraded more rapidly in serum $\left(t_{1 / 2}, 2-3 \mathrm{~h}\right)$ than G17 $\left(t_{1 / 2}, 3-5 h\right)$. EDTA blocked degradation at the COOH-terminus of both 2-17 G17 and G17 but cleavage at the $\mathrm{NH}_{2}$-terminus still occurred, giving rise to a G14-like peptide. The rate of conversion of G17 in serum was not enough to account for the production of fragments in vivo, and it is proposed that these are formed when G17 encounters enzymes on cell surfaces, perhaps during passage through the capillary circulation. The production of these fragments needs to be considered in interpreting studies of the identity, metabolism, and release of gastrin in health and disease.
\end{abstract}

\section{Introduction}

The predominant form of the acid-stimulating hormone gastrin that occurs in antral mucosa is the heptadecapeptide, G1 $17^{1}$

Dr. Pauwel's present address is Department of Nuclear Medicine, University of Louvain Medical School, B-1200 Brussels, Belgium. Address correspondence to Professor Dockray, The Physiology Laboratory, University of Liverpool, P.O. Box 147, Brownlow Hill, Liverpool, L69 3BX, U.K.

Received for publication 23 September 1983 and in revised form 6 February 1985

1. Abbreviations used in this paper: $\mathrm{G} 14, \mathrm{COOH}$-terminal tetradecapeptide fragment; G17, heptadecapeptide gastrin; 2-17 G17, hexadecapeptide; HPLC, high performance liquid chromatography.

J. Clin. Invest.

(c) The American Society for Clinical Investigation, Inc.

0021-9738/85/06/2006/08 $\$ 1.00$

Volume 75, June 1985, 2006-2013
(1-4). This molecule is rapidly cleared from the circulation with a half-life of 5-11 min in man, but little is known of the metabolic pathways involved and in particular whether or not it might be converted to shorter fragments (5-7). The latter would be biologically active if they included the $\mathrm{COOH}$ terminal tetrapeptide amide sequence, which is the minimal active fragment. We recently obtained preliminary evidence to indicate that G17 might be degraded by plasma enzymes to fragments with $\mathrm{COOH}$-terminal immunoreactivity (8). We have now used radioimmunoassay (RIA) employing a series of region specific antisera together with chromatographic separation by gel filtration, ion exchange chromatography, and high performance liquid chromatography (HPLC), to study the forms produced in vivo when G17 is infused intravenously and in vitro when $\mathrm{G} 17$ is incubated in serum. The results provide evidence for the production of both $\mathrm{COOH}$ - and $\mathrm{NH}_{2}-$ terminal fragments of $\mathrm{G} 17$. One of the $\mathrm{NH}_{2}$-terminal immunoreactive fragments has a relatively long half-life and becomes the predominant molecular species after stopping infusions of G17.

\section{Methods}

Peptides. Synthetic hG17, 2-17 hG17, and 1-13 hG17 were purchased from UCB Bioproducts (Brussels, Belgium)

Subjects. Studies were made on five normal male subjects (aged 22-40 yr) who were members of the laboratory or clinical staff, and were without gastrointestinal disease. All gave informed consent to the experiments, which were approved by the local ethical committee.

Experimental procedures. Two types of experiments were carried out. First, metabolism in vivo was studied during and after an intravenous infusion of G17. Second, the metabolism of G17 and 2$17 \mathrm{G} 17$ in vitro was studied after their addition to serum or EDTAtreated plasma.

In vivo metabolism. Subjects fasted from midnight before the test. An intravenous infusion of $0.15 \mathrm{M} \mathrm{NaCl}$ was given for a 45 -min control period at $42 \mathrm{ml} \cdot \mathrm{h}^{-1}$, followed by synthetic hG17 (400 $\mathrm{pmol} \cdot \mathrm{kg}^{-1} \cdot \mathrm{h}^{-1}$ ) for another $60 \mathrm{~min}$. After the infusion, the contents of the syringe were removed and stored at $-20^{\circ} \mathrm{C}$ before further analysis. In control experiments, it was established that there was negligible adsorption of G17 to the infusion lines in the present experimental conditions.

During each test, venous blood was drawn from the arm opposite that used for infusion. Degradation of peptides by plasma enzymes was inhibited by mixing the blood immediately in tubes containing EDTA and 1:10 o-phenanthroline, to give final concentrations of 2.7 and $5 \mathrm{mM}$, respectively. After centrifugation, plasma was stored at $-20^{\circ} \mathrm{C}$ before RIA or fractionation procedures. Blood samples of $5 \mathrm{ml}$ were taken every $15 \mathrm{~min}$ throughout the test and at 5-min intervals during the final 15 min of infusion. Concentrations of immunoreactive gastrin in the final three samples were not significantly different, indicating that a steady state had been attained; these samples were pooled for chromatography. After the infusion, samples were taken every minute for $5 \mathrm{~min}$, and then every $5 \mathrm{~min}$ for $30 \mathrm{~min}$.

In vitro metabolism. After an overnight fast, venous blood was 


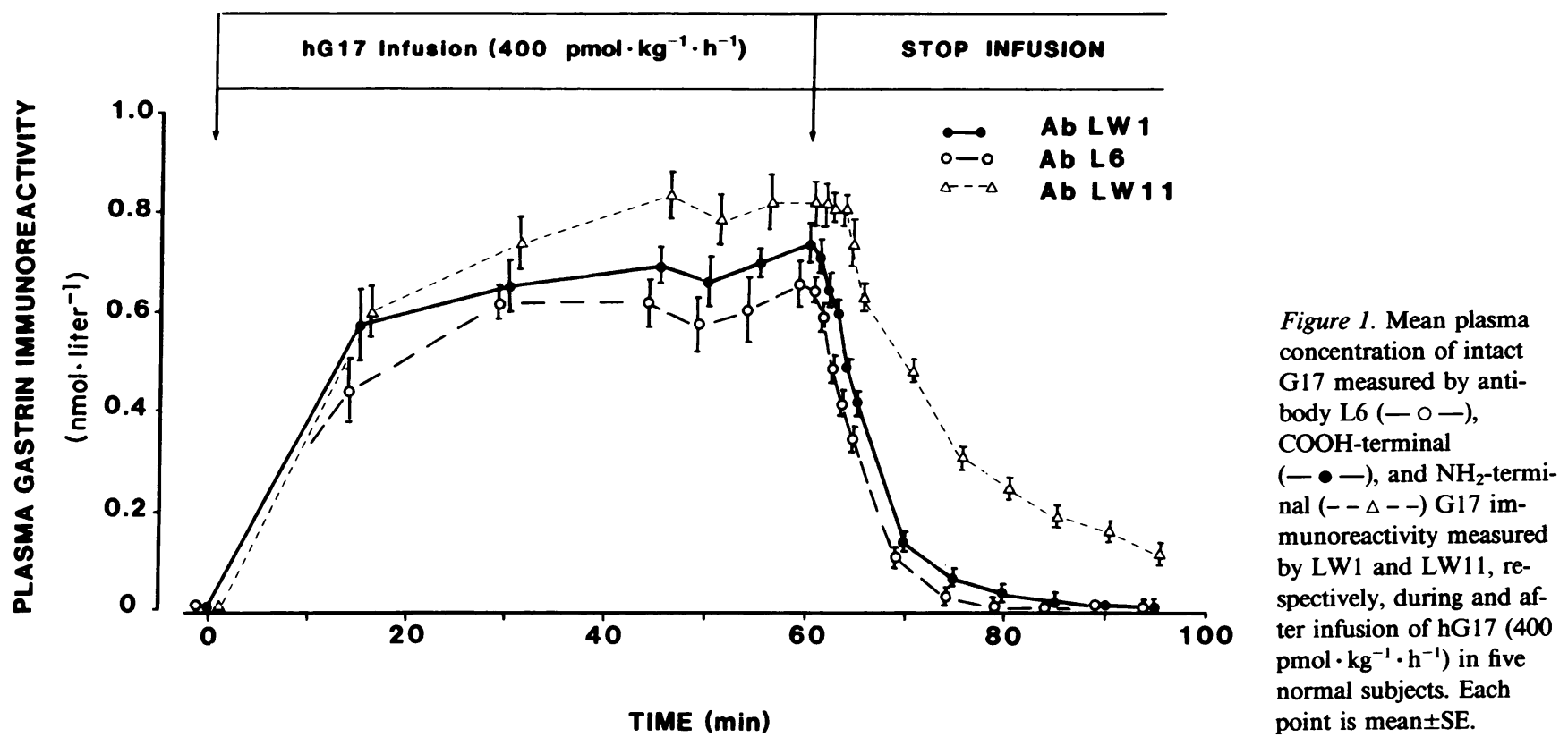

collected in aseptic conditions into sterile dry tubes or in tubes containing $2.7 \mathrm{mM}$ EDTA. The blood was centrifuged at $4^{\circ} \mathrm{C}(2,000$ $g, 10 \mathrm{~min}$ ) and serum or plasma was separated. Synthetic hG17, or its $\mathrm{COOH}$-terminal hexadecapeptide (2-17 G17), was added to the samples and incubated at 4,20 , or $37^{\circ} \mathrm{C}$ for $0,6,12$, and $24 \mathrm{~h}$. After incubation, the samples were immediately frozen in liquid nitrogen and stored at $-80^{\circ} \mathrm{C}$ before RIA or fractionation by gel filtration or ion-exchange chromatography.

Column chromatography. Serum or plasma samples were fractionated by gel filtration, ion-exchange chromatography, and HPLC. To obtain enough material for characterization, plasma samples collected during the final $15 \mathrm{~min}$ of the infusion of hG17 were separately pooled for each subject to give volumes of $15-20 \mathrm{ml}$. In some experiments, plasma samples from the five subjects were pooled together for chromatography. Four such samples of $20 \mathrm{ml}$ were separately processed: $(a)$ plasma collected just before the end of the infusion; $(b)$ plasma collected 2 and 3 min after stopping infusion; (c) plasma collected 5 , 10 , and $15 \mathrm{~min}$ after infusion; and $(d)$ plasma collected $20,25,30$, and $35 \mathrm{~min}$ after infusion.

Gel filtration. Samples were applied to Sephadex G-50 superfine columns $(1 \times 100 \mathrm{~cm})$ eluted with $0.05 \mathrm{M}$ phosphate, $\mathrm{pH} 7.5$ at $4^{\circ} \mathrm{C}$ with a constant flow rate of $6 \mathrm{ml} \cdot \mathrm{h}^{-1}$. Trace amounts of ${ }^{125} \mathrm{I}-\mathrm{Na}$ were added as a calibration marker; in addition, the void volume was routinely identified by the elution position of plasma proteins detected by $O D$ at $280 \mathrm{~nm}$. Columns were also calibrated on separate occasions with synthetic standard hG17 and 1-13 hG17.

Ion-exchange chromatography. Samples were applied to DEAE columns $(1 \times 15 \mathrm{~cm})$ with trace amounts of ${ }^{125} \mathrm{I}$ labeled $\mathrm{hG17}$ as a marker. After equilibration with $0.6 \%$ ammonium carbonate at $4^{\circ} \mathrm{C}$, the columns were eluted with a gradient from 0.6 to $6 \%$ ammonium carbonate using a $50-\mathrm{ml}$ mixing vessel and a constant flow rate of $10 \mathrm{ml} / \mathrm{h}$.

Reverse phase HPLC. Material from DEAE column eluates was separated by reversed-phase HPLC on a Techsil $\mathrm{C}_{18} 5 \mu \mathrm{m}(5 \times 250$ $\mathrm{mm}$ ) column using an Altex system. The samples were reduced in volume in a Speed-vac (Savant Instruments, Inc., Hicksville, NY) to 3-6 $\mathrm{ml}$ and $\mathrm{pH}$ was brought below 7.0 with trifluoroacetic acid. Elution was made with a gradient of acetonitrile in $0.05 \%$ trifluoroacetic acid. In separate runs the columns were calibrated with 1-13 G17 and synthetic hG17 in total quantities comparable to those in the test samples. Column eluates $(1 \mathrm{ml})$ were collected into $0.1 \mathrm{ml}$ of $1 \mathrm{M}$ ammonium bicarbonate; recovery was $90-100 \%$.

Gastrin RIA. Gastrin was estimated by RIA using three types of region specific antisera: (a) antiserum L6, which is in practice absolutely specific for G17 (9), (b), antiserum LW1, which was raised to hG17 conjugated to bovine serum albumin (BSA) and is $\mathrm{COOH}$-terminal specific (10), and (c) antiserum LW11, which was raised to 1-13 hG17 conjugated to $\mathrm{BSA}$, and is $\mathrm{NH}_{2}$-terminal specific (10).

${ }^{125}$ I-labeled synthetic hG17 was used for RIA $(11,12)$. The peptide was iodinated by the chloramine-T method and the reaction mixture was purified on $\mathrm{AE}$ cellulose. Incubation and separation conditions were as previously described $(8,10)$. With all antisera, assays were carried out using synthetic hG17I as standard. The concentration of hG17I for half maximal inhibition of binding was $2 \mathrm{fmol} \cdot \mathrm{ml}^{-1}$ for

Table I. Metabolism of hG17 Immunoreactivity in Five Normal Subjects (Mean \pm SE) Infused with hG17 Measured with Antibodies L6, LWI, and LW11

\begin{tabular}{lllrr}
\hline Antisera & hG17 Infusion rate & Plasma plateau level & Half-life & Metabolic clearance rate \\
\hline & $p m o l \cdot \mathrm{kg}^{-1} \cdot \mathrm{h}^{-1}$ & $\mathrm{pmol} \cdot \mathrm{l}^{-1}$ & $\mathrm{~min}$ & $\mathrm{ml} \cdot \mathrm{kg}^{-1} \cdot \mathrm{min}^{-1}$ \\
L6 & $396 \pm 6$ & $617 \pm 47$ & $3.23 \pm 0.17$ & $10.97 \pm 0.91$ \\
LW1 & $389 \pm 11$ & $691 \pm 34$ & $4.88 \pm 0.08$ & $9.52 \pm 0.68$ \\
LW11 & $406 \pm 10$ & $815 \pm 49$ & $11.71 \pm 0.60$ & $8.44 \pm 0.57$
\end{tabular}


$\mathrm{LW} 1,1 \mathrm{fmol} \cdot \mathrm{ml}^{-1}$ for LW11, and $2.5 \mathrm{fmol} \cdot \mathrm{ml}^{-1}$ for L6. In assays in which $>20 \mu$ l of plasma was added to the tube (up to a maximum of $100 \mu \mathrm{l})$, the standard curves were prepared with an appropriate volume of plasma stripped of gastrin. The detection limit of gastrin immunoreactivity in plasma ranged from 3 to $10 \mathrm{pmol} \cdot \mathrm{l}^{-1}$ depending on the antiserum.

Analysis of the data. All results are expressed as mean \pm SEM, and the infusion data is analyzed here according to the plateau principle. Plasma steady-state gastrin concentrations were taken as the mean of values obtained during the final $15 \mathrm{~min}$ of infusion of hG17. The plasma gastrin concentrations after stopping the infusion were converted to the natural logarithm, and linear regression of In plasma gastrin vs. time was computed to yield the slope, from which the half-life $\left(t_{1 / 2}\right)$ was determined by dividing into 0.693 . The metabolic clearance rate, expressed in $\mathrm{ml} \cdot \mathrm{kg}^{-1} \cdot \mathrm{min}^{-1}$, was calculated by dividing the infused dose in $\mathrm{pmol} \cdot \mathrm{kg}^{-1} \cdot \mathrm{min}^{-1}$, by the plateau increment in plasma gastrin in pmol $\cdot 1^{-1}$. The apparent volume of distribution, expressed as $\mathrm{ml} \cdot \mathrm{kg}^{-1}$, was obtained by dividing the infusion rate by the product of plateau concentration and the slope of regression for disappearance.

\section{Results}

In vivo metabolism. The effective infusion rate of hG17 measured with L6, LW1, and LW11 was $396 \pm 6,389 \pm 11$, and $406 \pm 10 \mathrm{pmol} \cdot \mathrm{kg}^{-1} \cdot \mathrm{h}^{-1}$, respectively, as estimated by RIA of the solutions remaining in the syringe after infusion. Gel filtration and ion-exchange chromatography of this material showed a single peak with the chromatographic and immunochemical properties of standard hG17.

During the initial saline infusion, plasma gastrin immunoreactivity was undetectable with $\mathrm{L} 6\left(<10 \mathrm{pmol} \cdot \mathrm{1}^{-1}\right)$, was $10.1 \pm 2.6 \mathrm{pmol} \cdot 1^{-1}$ with antiserum $\mathrm{LW} 1$, and was $10.0 \pm 0.7$ pmol $\cdot 1^{-1}$ with antiserum LW11. 30 min after beginning infusion of hG17, plasma gastrin immunoreactivity reached a plateau level. The mean plateau concentration with the $\mathrm{NH}_{2}-$

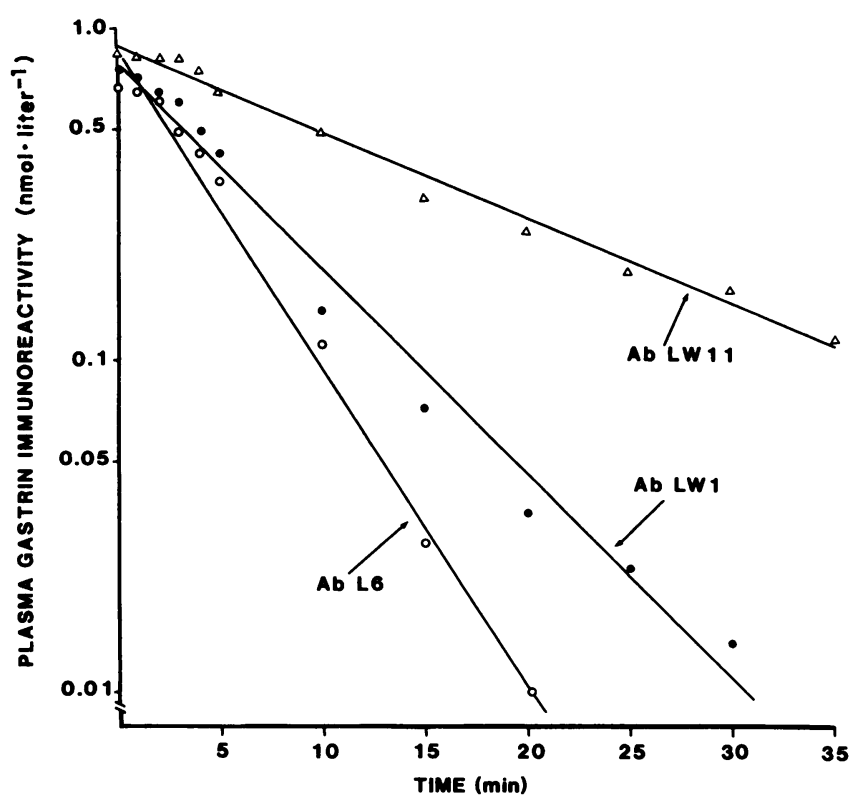

Figure 2. Disappearance of intact G17 (0), $\mathrm{COOH}$-terminal (๑), and $\mathrm{NH}_{2}$-terminal $(\Delta)$ immunoreactivity after stopping infusion of hG17. See Fig. 1 for further details. terminal specific antibody, LW 11 , was $\sim 30 \%$ higher than with antibody L6, which measures intact G17. The plateau concentration with the $\mathrm{COOH}$-terminal specific antibody, LW1, was $\sim 15 \%$ higher than with L6 (Fig. 1 and Table I). The metabolic clearance rate, volume of distribution, and half-life determined with antibodies L6, LW1, and LW11 are given in Table I. Of particular interest is the difference in half-lives measured by different antibodies; thus, intact circulating G17 (read by L6) disappeared with a calculated mean half-life of $3.23 \pm 0.17 \mathrm{~min}$, whereas total $\mathrm{COOH}$-terminal and $\mathrm{NH}_{2}$-terminal $\mathrm{G} 17 \mathrm{immu}$ noreactivity disappeared slower with half-lives of $4.88 \pm 0.08$ min and $11.71 \pm 0.60 \mathrm{~min}$, respectively (Fig. 2 and Table I).

Molecular forms. Gel filtration of plasma samples taken during the plateau phase of the infusion revealed in each subject a major peak of activity eluting in the position of the standard (Fig. 3) and read equally by the three antisera. In addition, there was a peak of late-eluting $\mathrm{COOH}$-terminal
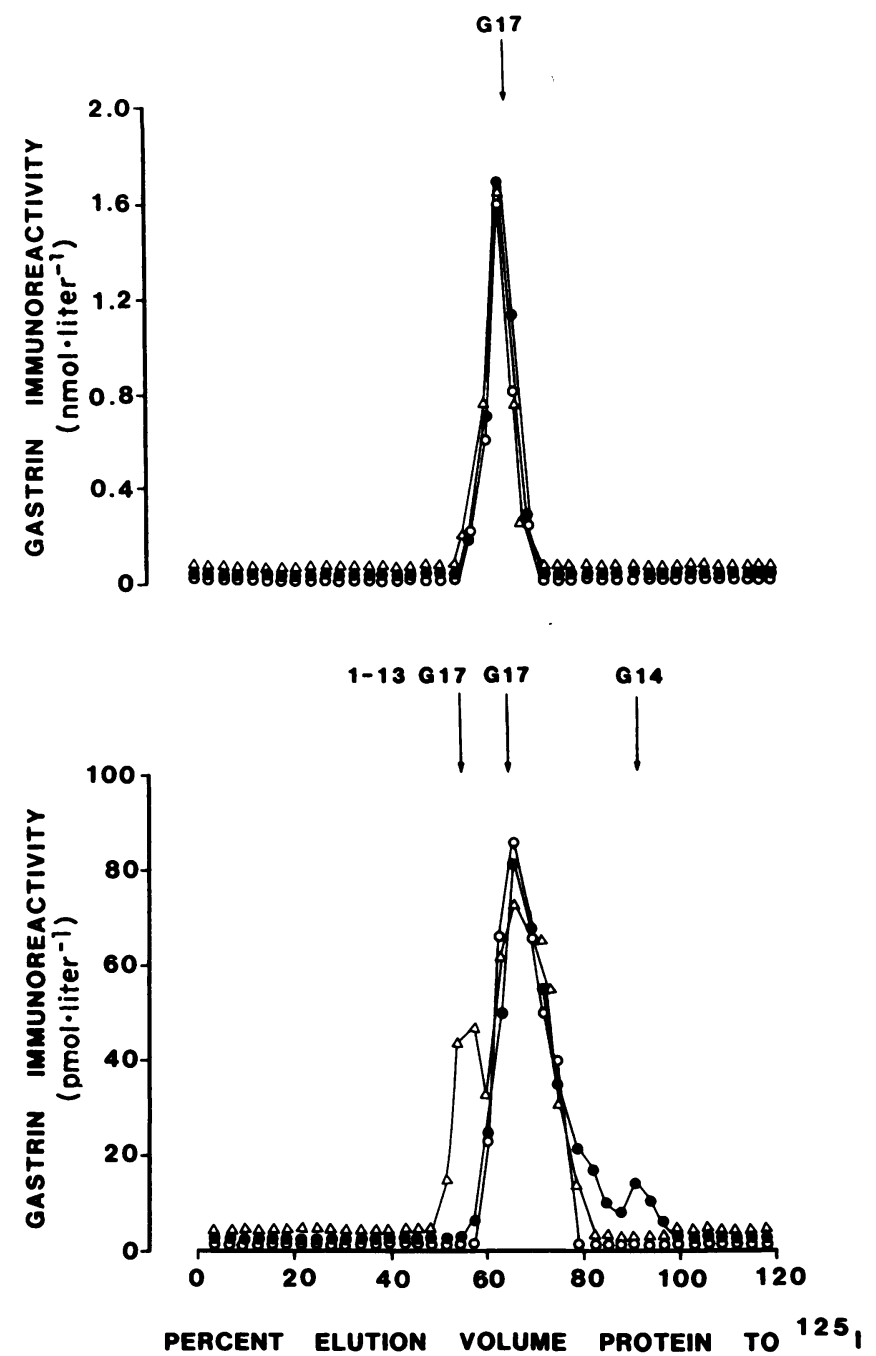

Figure 3. Sephadex G50 elution profile of standard G17 (top) and plasma taken during the plateau phase of intravenous infusion of G17 (bottom) in a normal human subject. The columns were assayed

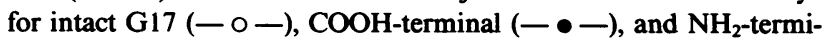
nal $(-\Delta-)$ immunoreactivity. See also Fig. 1. 
immunoreactive material measured by $L W 1$, and a peak of $\mathrm{NH}_{2}$-terminal gastrin immunoreactivity eluting just before G17 revealed by $L W 11$.

Ion-exchange chromatography of plasma samples taken during the plateau phase also revealed in each subject a major peak coeluting with standard G17 and reacting with all three antibodies (Fig. 4). In addition, antibody LW1 revealed a peak of $\mathrm{COOH}$-terminal activity (18\% total) that eluted later and progressively declined after stopping the infusion. Moreover, antiserum LW11 revealed two further peaks of $\mathrm{NH}_{2}$-terminal G17 immunoreactivity. These eluted close to each other and just in front of hG17; they probably coeluted on gel filtration. Peak II corresponded in elution position to $1-13$ G17 standard. Tubes corresponding to peaks $\mathrm{I}$ and II of $\mathrm{NH}_{2}$-terminal immunoreactivity were also fractionated by HPLC. Peak II emerged as a single peak that again had the retention time of 1-13 G17, and Peak I emerged 2-3 min earlier, indicating a less basic and less hydrophobic peptide (Fig. 5). In plasma samples collected after the infusion, the same peaks of $\mathrm{NH}_{2}-$ terminal activity were found. However, the two earlier eluting peaks increased from $26 \%$ of total $\mathrm{NH}_{2}$-terminal immunoreactivity during the infusion to $75 \%$ in the $20-35-\min$ samples

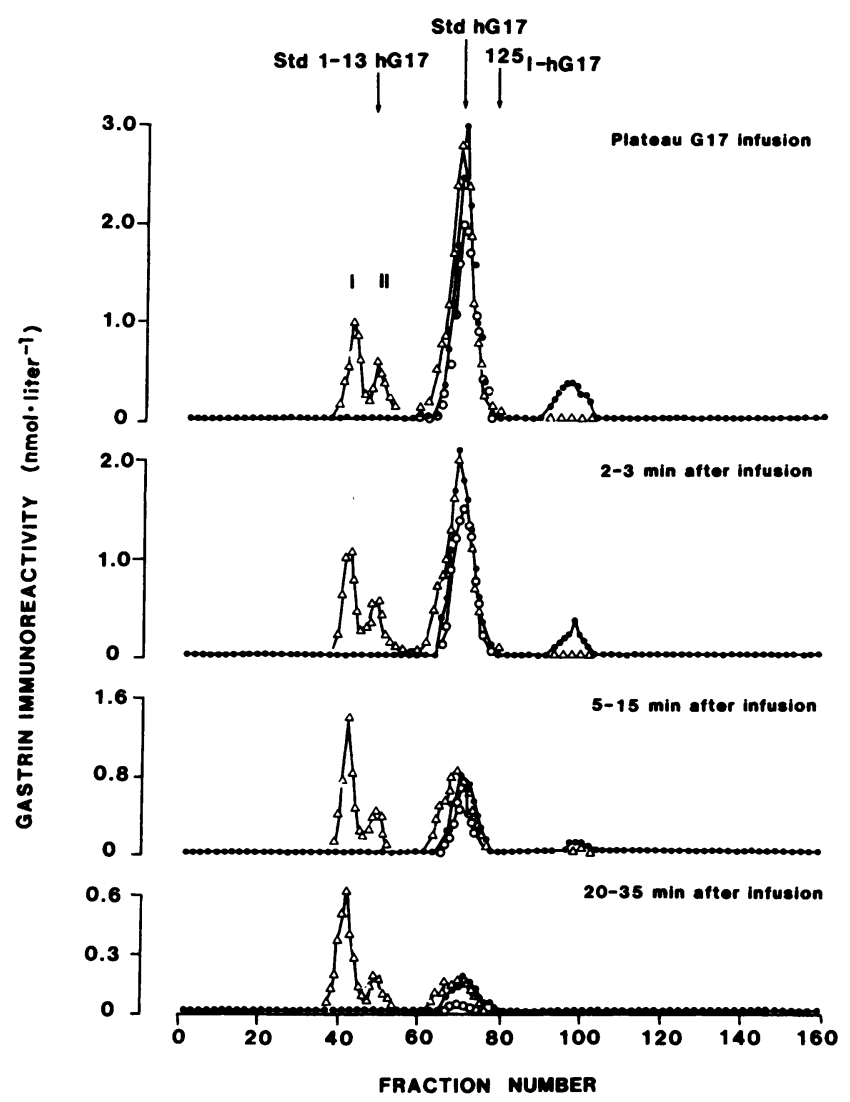

Figure 4. Ion exchange chromatography on DEAE cellulose of plasma taken during the plateau phase of intravenous infusion of G17 (top), and at intervals (2-3, 5-15, and 20-35 min) after stopping infusion of G17. Arrows at the top indicate elution position of standards. ${ }^{125}$ I-hG17 was added routinely to samples, and 1-13 hG17 or G17 were run in separate experiments. Note the increase in relative concentrations of the early eluting $\mathrm{NOOH}$-terminal fragment after stopping infusion. Symbols are as in Fig. 1.

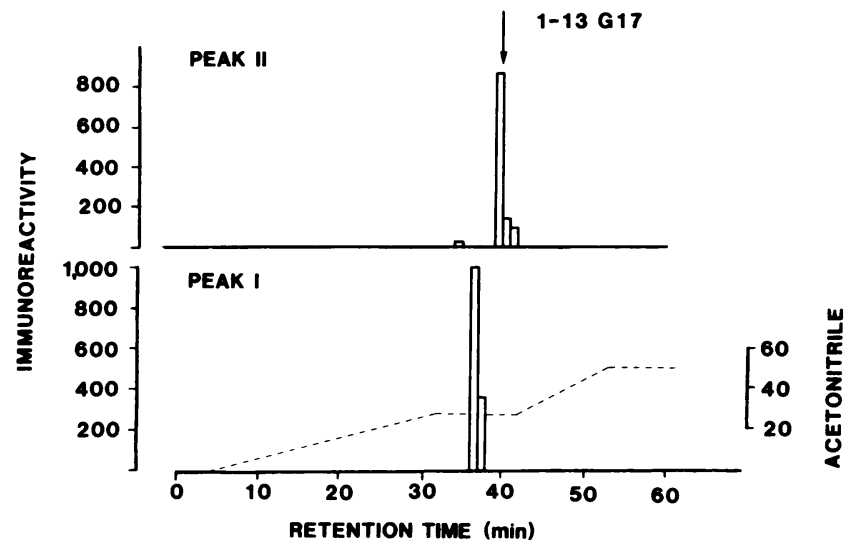

Figure 5. Separation by reversed phase HPLC on Techsil $\mathrm{C}_{18}$ of tubes in DEAE column eluates corresponding to peaks I and II of $\mathrm{NH}_{2-}$ terminal immunoreactivity. Samples were concentrated in a Speedvac and $\mathrm{pH}$ was taken to below 7 before injection. Gradient elution was carried out with acetonitrile (-----). Arrow at top indicates the retention time of standard 1-13 G17; in this system intact $\mathrm{G} 17$ has a retention time of $55 \mathrm{~min}$. Assays with LW11.

after stopping the infusion (Fig. 4). The peak corresponding to hG17 was proportionally reduced (Table II).

In vitro metabolism. All antisera revealed a time-dependent and temperature-dependent decrease of immunoreactivity when G17 was incubated in serum (Fig. 6). The $\mathrm{COOH}$-terminal and $\mathrm{NH}_{2}$-terminal $\mathrm{Gl} 7$ immunoreactivities were slower to disappear than intact G17-immunoreactivity measured by L6. This suggests that both $\mathrm{NH}_{2-}$ and $\mathrm{COOH}$-terminal fragments of $\mathrm{G} 17$ were produced during the incubation, and that the degradation of these was slower than that of intact G17. In support of this, gel filtration studies revealed a major peak with the properties of the intact heptadecapeptide together with an additional peak of $\mathrm{COOH}$-terminal immunoreactivity eluting after $\mathrm{G} 17$ and a peak of $\mathrm{NH}_{2}$-terminal immunoreactivity eluting just before, and imperfectly separated from, G17 (Fig. 7). The $\mathrm{COOH}$-terminal and $\mathrm{NH}_{2}$-terminal immunoreactive components were also separated on ion exchange chromatography (Fig. 8).

Addition of EDTA prevented the loss of immunoreactivity with the COOH-terminal antibody LW1, but not with LW11 and L6 (Fig. 6). Gel filtration (not shown) and ion exchange chromatography (Fig. 9) suggested that in these samples there was material with the properties of G17 together with a $\mathrm{COOH}$-terminal fragment that increased in concentration during incubation and that had similar chromatographic properties to the $\mathrm{COOH}$-terminal fragment generated in vivo. There was also a minor peak of $\mathrm{NH}_{2}$-terminal immunoreactive material. A third peak of $\mathrm{COOH}$-terminal immunoreactivity was read by antiserum LW1 in samples after prolonged incubation. This material eluted just in front of G17 and was not well resolved from it. Total $\mathrm{COOH}$-terminal immunoreactivity was relatively constant, so that the two $\mathrm{COOH}$-terminal fragments generated during incubation became progressively more important and finally accounted for close to $100 \%$ of the total $\mathrm{COOH}$-terminal activity.

When 2-17 G17 was incubated in serum, there was a time-dependent and temperature-dependent loss of immunoreactivity, which was about twice that of G17 (Fig. 10). EDTA 
Table II. COOH-terminal and $\mathrm{NH}_{2}$-terminal Gastrin Immunoreactive Forms Separated by Ion Exchange Chromatography in Plasma Pools of Fire Subjects During and After Infusion of hG17 (400 pmol $\left.\cdot \mathrm{kg}^{-1} \cdot \mathrm{h}^{-1}\right)^{*}$

\begin{tabular}{|c|c|c|c|c|c|c|c|c|}
\hline & \multirow{3}{*}{$\begin{array}{l}\text { G17 } \\
\text { measured by } \\
\text { antibody } L 6\end{array}$} & \multirow{2}{*}{\multicolumn{3}{|c|}{ CT-G17 measured by antibody LW1 }} & \multicolumn{4}{|c|}{ NT-G17 measured by antibody LW11 } \\
\hline & & & & & \multirow[b]{2}{*}{ Total } & \multirow[b]{2}{*}{ G17 } & \multicolumn{2}{|l|}{ NT-G17 } \\
\hline & & Total & G17 & CT-G17 & & & Peak I & Peak II \\
\hline Plasma pool during infusion & 532 & 708 & $580(82 \%)$ & $128(18 \%)$ & 860 & $636(74 \%)$ & $139(16 \%)$ & $85(10 \%)$ \\
\hline \multicolumn{9}{|l|}{ Plasma pools after infusion } \\
\hline 2-3 min & 386 & 563 & $490(87 \%)$ & $73(13 \%)$ & 824 & $560(68 \%)$ & $172(21 \%)$ & $92(11 \%)$ \\
\hline $5-15 \mathrm{~min}$ & 180 & 262 & $231(88 \%)$ & $31(12 \%)$ & 515 & $237(46 \%)$ & $231(45 \%)$ & $99(19 \%)$ \\
\hline $20-35 \mathrm{~min}$ & 5 & 30 & $30(100 \%)$ & $-(0 \%)$ & 190 & $46(24 \%)$ & $118(62 \%)$ & $26(14 \%)$ \\
\hline
\end{tabular}

* Values are presented as pmol $\cdot 1^{-1}$ equivalent of plasma. Values in parenthesis give the percentages of each component of total immunoreactivity measured by antibody LW1 or LW11. CT-G17, COOH-terminal G17; NT-G17, $\mathrm{NH}_{2}$-terminal G17.

completely inhibited the loss of immunoreactivity. Separation by ion-exchange chromatography indicated that in both serum and EDTA-treated plasma there was conversion to a more

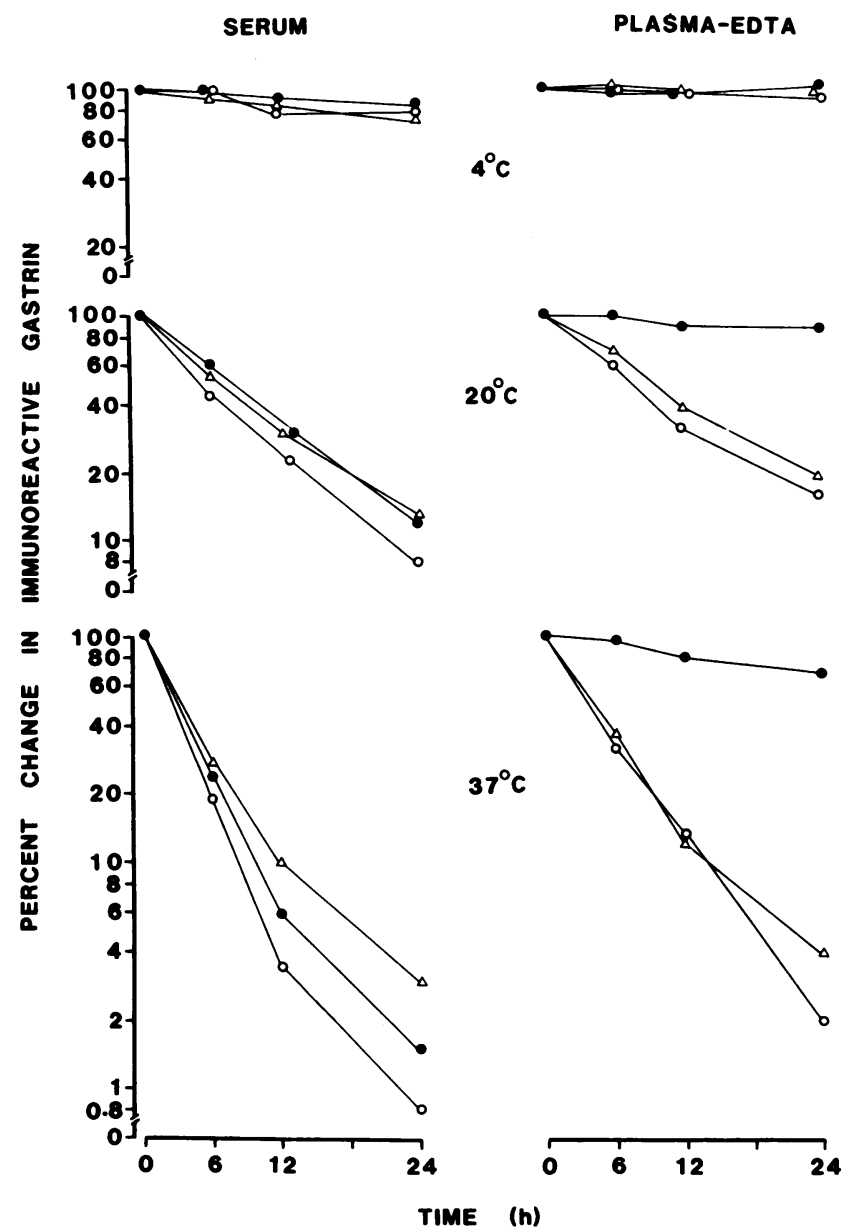

Figure 6. Loss of immunoreactivity when hG17 was incubated in human serum at 4,20 , or $37^{\circ} \mathrm{C}$ for up to $24 \mathrm{~h}($ left), and the effects of EDTA (right). Samples were assayed with three antibodies (see Fig. 1). Note that EDTA stops the loss of $\mathrm{COOH}$-terminal immunoreactivity but not that of $\mathrm{NH}_{2}$-terminal and intact $\mathrm{G} 17$ immunoreactivity. - $\bullet$, antibody LW1; - O , antibody L6; $-\Delta-$, antibody LW11. acidic $\mathrm{COOH}$-terminal fragment (Fig. 11), and with prolonged incubation there was further accumulation of a molecular species that was less acidic than 2-17 G17. Presumably EDTA stops the further degradation of the $\mathrm{COOH}$-terminal fragments.

\section{Discussion}

The principal finding of this study is that $\mathrm{G} 17$ can be converted to $\mathrm{COOH}$-terminal and $\mathrm{NH}_{2}$-terminal immunoreactive fragments in the human circulation in vivo, and in serum incubated in vitro. There have been many previous studies of the concentrations, identity, and metabolism of G17-like immunoreactivity in the human circulation, but little attention has been given to the possibility of its conversion to smaller forms.

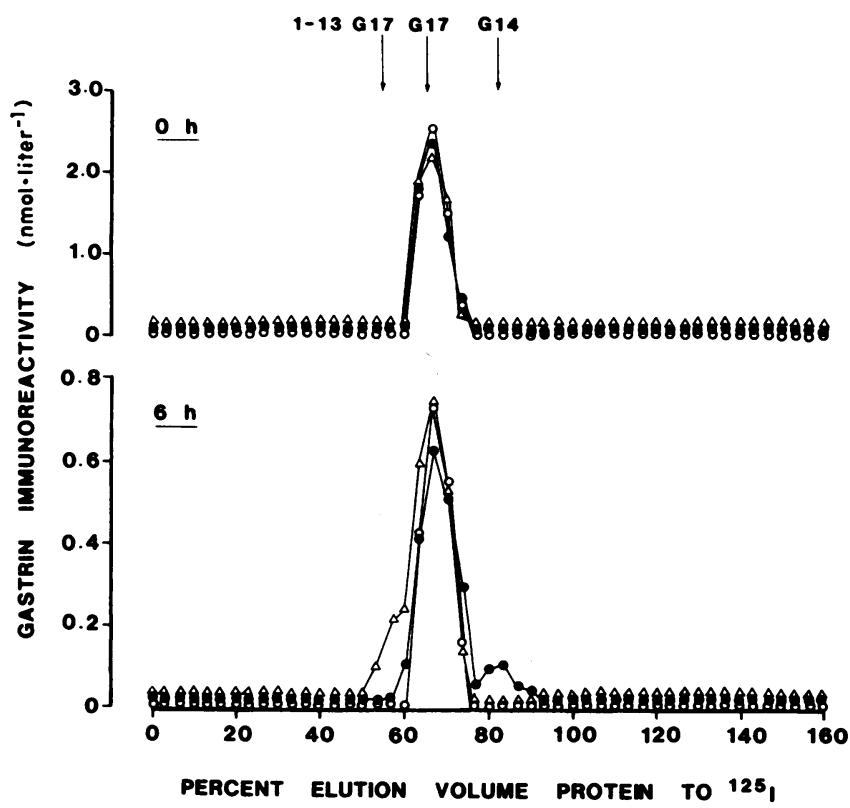

Figure 7. Separation on Sephadex G50 superfine $(1 \times 100 \mathrm{~cm})$ of synthetic hG17 before (top) and $6 \mathrm{~h}$ after incubation in serum at $37^{\circ} \mathrm{C}$ (bottom). Columns were assayed with the same antibodies as used in Fig. 1. Note that after $6 \mathrm{~h}$ incubation there was a late running peak of $\mathrm{COOH}$-terminal immunoreactivity and an imperfectly separated peak of $\mathrm{NH}_{2}$-terminal immunoreactivity emerging before G17. 


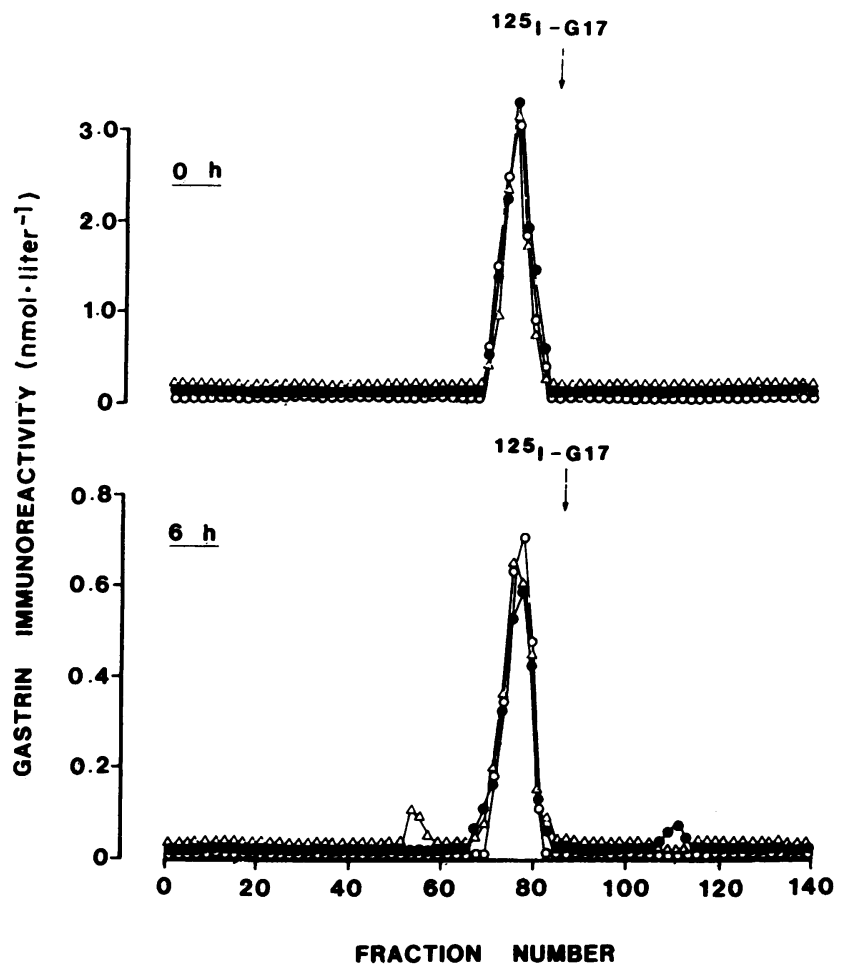

Figure 8. Separation on DEAE Cellulose $(1 \times 15 \mathrm{~cm})$ of human G17 before (top) and $6 \mathrm{~h}$ after incubation in serum at $37^{\circ} \mathrm{C}($ bottom). See legend to Fig. 1 for further details about antibodies. Note the lateeluting peak of $\mathrm{COOH}$-terminal immunoreactivity and the early eluting peak of $\mathrm{NH}_{2}$-terminal immunoreactivity, in addition to G17immunoreactivity. Columns were calibrated with ${ }^{125} \mathrm{I}-\mathrm{G} 17$, indicated by the arrow.

Indeed, for practical purposes it often seems to have been assumed that $\mathrm{G} 17$ is stable in human plasma. Our results show that this assumption is unjustified. In species such as dog and cat, it is already well established that circulating G17 is converted in the circulation to $\mathrm{COOH}$-terminal immunoreactive fragments (13-15). The main difference between dog, cat, and man lies in the rate of the conversion. Thus in dog, intact $\mathrm{G} 17$ and $\mathrm{NH}_{2}$-terminal immunoreactive fragments are virtually absent from the systemic circulation (13), whereas in man $\mathrm{COOH}$-terminal or $\mathrm{NH}_{2}$-terminal immunoreactive fragments generated from $\mathrm{G} 17$ occur in concentrations up to $\sim 25 \%$ of total G17 immunoreactivity.

The main $\mathrm{COOH}$-terminal product of $\mathrm{G17}$ metabolism both in vivo and in vitro has the properties of minigastrin, which is known now to be the $\mathrm{COOH}$-terminal tetradecapeptide fragment, $\mathrm{G} 14$ (16). One of the two $\mathrm{NH}_{2}$-terminal immunoreactive forms generated in vivo had the properties of 1-13 G17. The other $\mathrm{NH}_{2}$-terminal product is probably a fragment of $1-13 \mathrm{G} 17$, since we found closely similar material produced when 1-13 G17 was infused intravenously in humans (10). Both G14 and 1-13 G17 have previously been reported to occur in the human peripheral circulation $(11,17)$. The same forms have also been reported in extracts of antral mucosa, or gastrinoma tissue, and have been isolated and sequenced from these sources $(16,18,19)$. It is generally thought that in man the circulating peptides are derived intact from the tissue

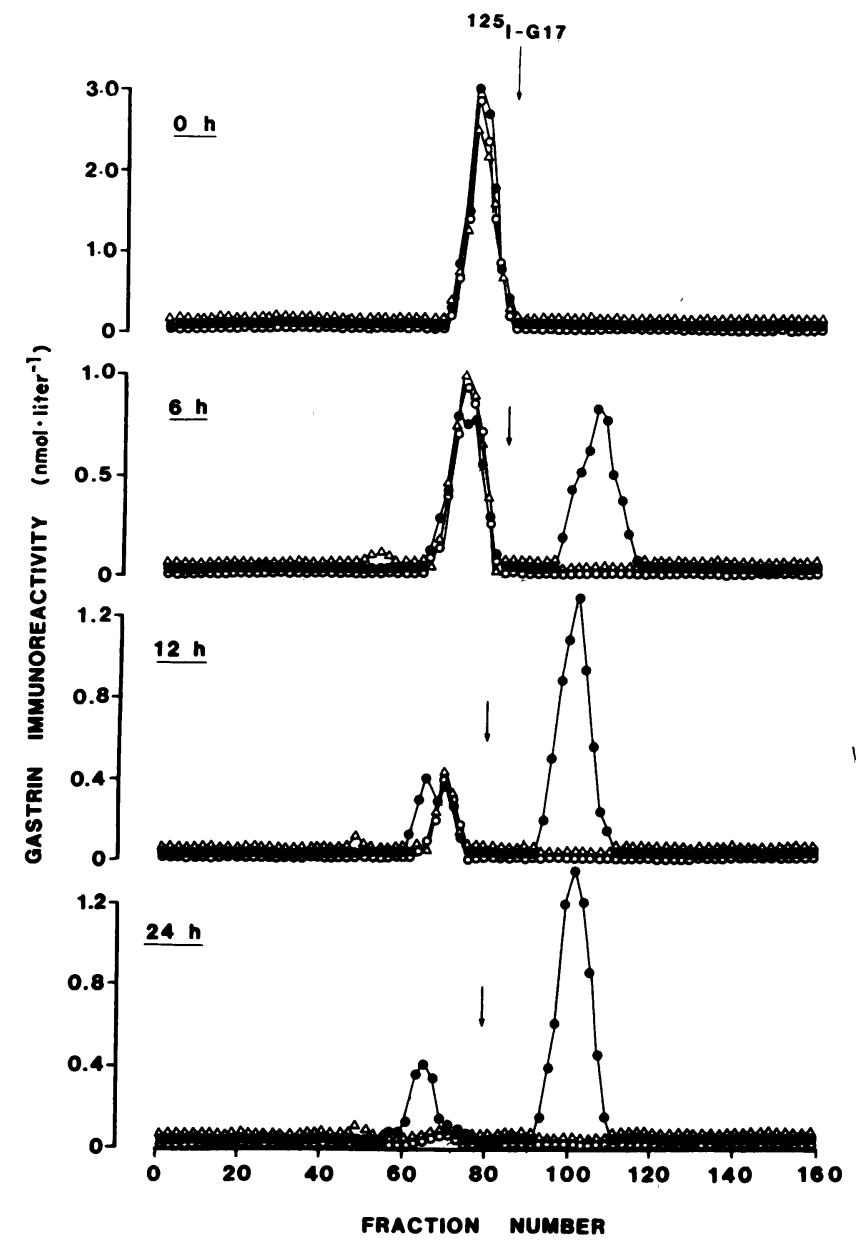

Figure 9. Separation on DEAE cellulose of samples 6, 12, and $24 \mathrm{~h}$ after incubation of hG17 in plasma containing EDTA. See legend to Fig. 1 for further details.

stores. This study indicates that this need not be true. Instead, a proportion of the circulating pools of these peptides could be obtained by cleavage of $\mathrm{G} 17$ following secretion. We found that after stopping an infusion of $\mathrm{G} 17$ the $\mathrm{NH}_{2}$-terminal fragments accounted for progressively greater proportions of total immunoreactivity until they were the predominant immunoreactive forms; presumably these fragments have a longer half-life than G17.

The conversion of $\mathrm{G} 17$ to $\mathrm{COOH}$-terminal fragments like G14 is not likely to make a significant change in circulating gastrin biological activity because long $\mathrm{COOH}$-terminal fragments are equipotent with G17 (20). It is generally thought that $\mathrm{NH}_{2}$-terminal fragments of $\mathrm{Gl} 7$ are inactive, so that conversion of $\mathrm{G} 17$ to $1-13 \mathrm{G17}$ would reduce activity. However, if $1-13$ G17 was generated by the action of an endopeptidase, the $\mathrm{COOH}$-terminal tetrapeptide might be produced as a coproduct and this is the minimal fragment with biological activity. The potency of the tetrapeptide is about 10 times less than that of $\mathrm{G} 17$ for acid secretion. In this study it would have escaped detection because it reacts weakly with the COOH-terminal antibody LW1. It should also be noted that Petersen et al. (21) have recently reported that 1-13 G17 


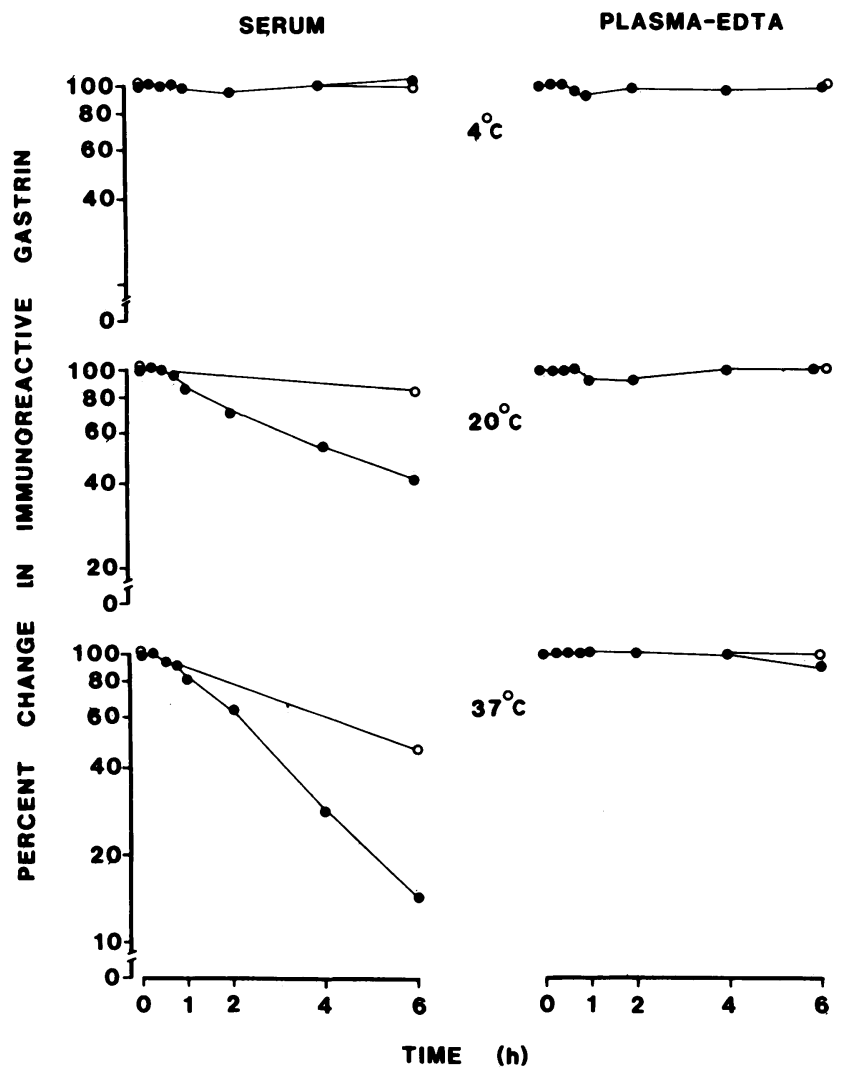

Figure 10. Comparison of the stability of hG17 (o- - ) and 2-17 HG17 (- ) in serum and in plasma collected in EDTA during incubations at 4,20 , and $37^{\circ} \mathrm{C}$ for periods up to $6 \mathrm{~h}$. All samples were assayed with a $\mathrm{COOH}$-terminal specific antibody (LW1).

inhibited acid secretion. Cleavage of G17 to 1-13 G17 might therefore generate inhibitory activity in the circulation. However, we have been unable to confirm the observations of Petersen et al., so that for now the significance of circulating 1-13 G17 for acid secretion remains in doubt (10).

To determine if the conversion of $\mathrm{G} 17$ to $\mathrm{COOH}$-terminal and $\mathrm{NH}_{2}$-terminal fragments was due to the action of serum enzymes, we performed a series of incubation experiments in vitro. We found that in serum there are enzyme systems that can degrade G17 to G14-like and 1-13 G17-like peptides, as well as to forms not recognized by $\mathrm{COOH}$-terminal or $\mathrm{NH}_{2-}$ terminal specific antibodies. The hexadecapeptide (2-17 G17) was degraded more rapidly than $\mathrm{G} 17$, indicating a protective function for the $\mathrm{NH}_{2}$-terminal pyroglutamyl residue in G17. In the presence of EDTA both $\mathrm{G} 17$ and 2-17 G17. were converted to $\mathrm{COOH}$-terminal immunoreactive peptides that were resistant to further degradation, so that one of the enzymes acting at the $\mathrm{NH}_{2}$-terminus is presumably a metalloenzyme.

The rate of conversion of $\mathrm{G} 17$ to $\mathrm{COOH}$-terminal and $\mathrm{NH}_{2}$-terminal fragments in vitro, and the subsequent degradation to nonimmunoreactive fragments was relatively slow; for example, at $37^{\circ} \mathrm{C}$ the half-life measured by L6 was 3-5 h. In contrast, the half-life of intact $\mathrm{G} 17$ in vivo is $<5 \mathrm{~min}$. Evidently the plasma enzyme systems we have identified are not likely to be of physiological importance in the clearance

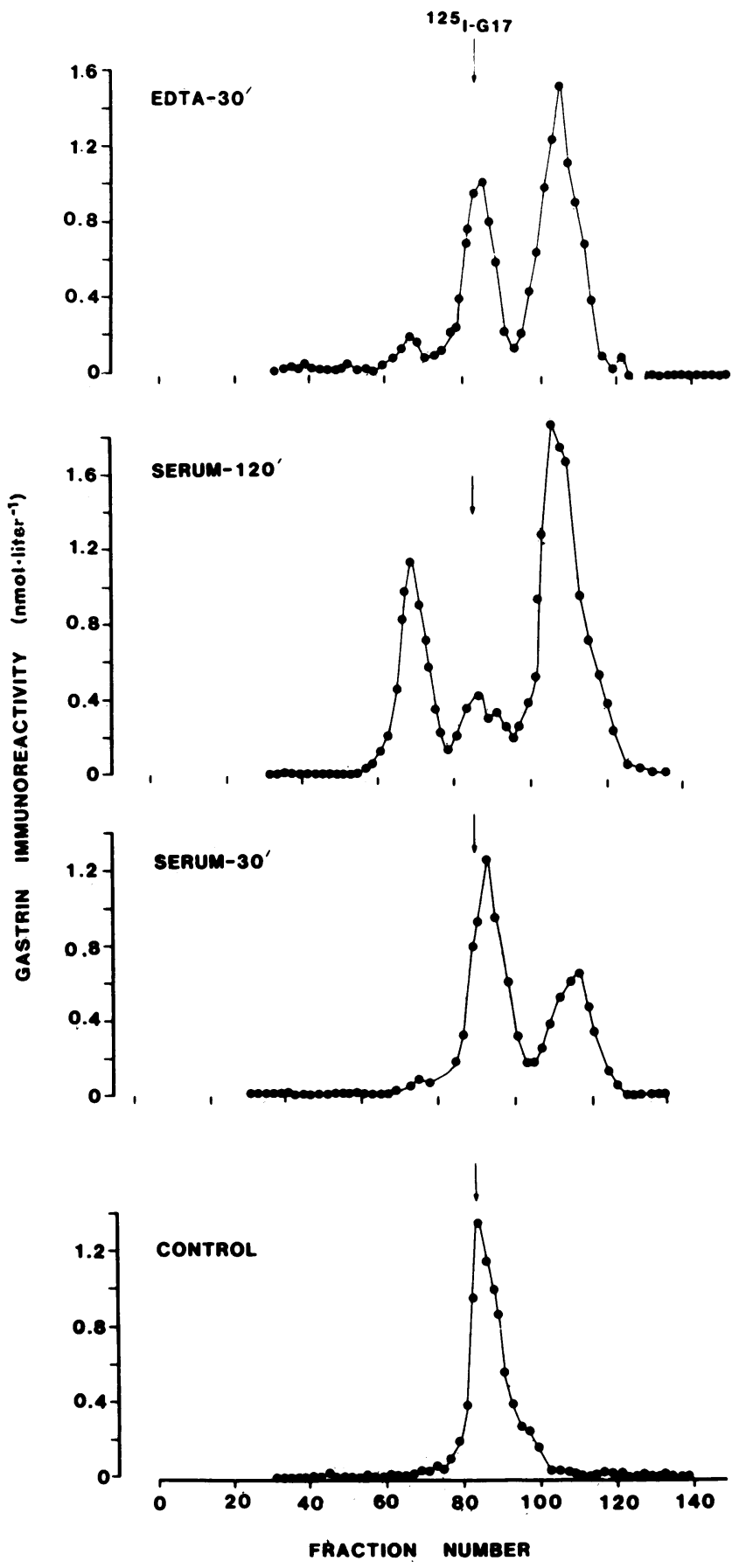

Figure 11. Separation on DEAE Cellulose of samples taken before (bottom) and during incubation of 2-17 hG17 in serum for $30 \mathrm{~min}$ and $120 \mathrm{~min}$, and in plasma containing EDTA. Assays with $\mathrm{COOH}-$ terminal specific antiserum, LW1. Note the progressive appearance in serum of a G14-like peptide (elution volume, 110-115 ml) followed by an earlier-eluting peptide $(60-70 \mathrm{ml})$. In EDTA-treated samples the G14-like component predominates.

of $\mathrm{G} 17$. We have previously observed that in dog, there is also degradation of $\mathrm{G} 17$ by plasma enzymes to $\mathrm{COOH}$-terminal fragments, and again the rates of conversion are relatively slow (although faster than in humans) (13). Because plasma enzymes 
are unable to account for the rate of conversion in vivo, it has been postulated that enzymes either on or near the capillary endothelial cells mediate the conversion (13). Similar systems have also been postulated to account for the production of fragments of the $\mathrm{NH}_{2}$-terminal tryptic peptide of $\mathrm{G} 34$ that have been found in the peripheral circulation in man (22).

The present findings emphasize the care that must be taken in processing samples for gastrin RIA and in interpretation of the results of studies of gastrin molecular forms. They also indicate the importance of using several region specific antisera together with chromatographic separation in studying the physiology and pathophysiology of this hormone.

\section{References}

1. Gregory, R. A., and H. J. Tracy. 1964. The constitution and properties of two gastrins extracted from hog antral mucosa. Gut. 5: 103-117.

2. Berson, S. A., and R. S. Yalow. 1971. Nature of immunoreactive gastrin extracted from tissues of gastrointestinal tract. Gastroenterology. 60:215-222.

3. Malmstrom, J., F. Stadil, and J. F. Rehfeld. 1976. Gastrins in tissue: concentration and component pattern in gastric, duodenal and jejunal mucosa of normal human subjects and patients with duodenal ulcer. Gastroenterology. 70:697-703.

4. Calam, J., G. J. Dockray, R. Walker, H. J. Tracy, and D. Owens. 1980. Molecular forms of gastrin in peptic ulcer: comparison of serum and tissue concentrations of G17 and G34 in gastric and duodenal ulcer subjects. Eur. J. Clin. Invest. 10:241-247.

5. Schrumpf, E., L. S. Semb, and H. Vold. 1973. Metabolic clearance and disappearance rates of synthetic human gastrin in man. Scand. J. Gastroenterol. 8:731-734.

6. Walsh, J. H., J. I. Isenberg, J. Ansfield, and V. Maxwell. 1976. Clearance and acid stimulating action of human big and little gastrin in duodenal ulcer subjects. J. Clin. Invest. 57:1125-1131.

7. Boniface, J., D. Picone, M. Schebaline, A. M. Zfass, and G. M. Makhlouf. 1976. Clearance rate, half-life and secretory potency of human gastrin-17-I in different species. Gastroenterology. 71:291-294.

8. Pauwels, S., and G. J. Dockray. 1982. Identification of $\mathrm{NH}_{2}-$ terminal fragments of big gastrin in plasma. Gastroenterology. 82:5661.

9. Dockray, G. J., and I. L. Taylor. 1976. Heptadecapeptide gastrin: measurement in blood by specific radioimmunoassay. Gastroenterology. 71:971-976.

10. Pauwels, S., G. J. Dockray, R. Walker, and S. Marcus. 1985. Metabolism of 1-13 G17 in man and failure to influence acid secretion. Gastroenterology. In press.

11. Dockray, G. J., and J. H. Walsh. 1975. Amino terminal gastrin fragment in serum of Zollinger-Ellison syndrome patients. Gastroenterology. 68:222-230.

12. Dockray, G. J., J. H. Walsh, and M. I. Grossman. 1976. Biological activity of iodinated gastrins. Biochem. Biophys. Comm. 69: 339-345.

13. Dockray, G. J., R. A. Gregory, H. J. Tracy, and W. Y. Zhu. 1982. Post-secretory processing of heptadecapeptide gastrin: conversion to C-terminal immunoreactive fragments in the circulation of the dog. Gastroenterology. 83:224-232.

14. Uvnas-Wallensten, K., and J. F. Rehfeld. 1976. Molecular forms of gastrin in antral mucosa, plasma and gastric juice during vagal stimulation of anesthetized cats. Acta Physiol. Scand. 98:217226.

15. Blair, E. L., E. R. Grund, P. K. Lund, and D. J. Sanders. 1977. A possible origin of circulating gastrin component IV in cats. $J$. Physiol. 273:561-572.

16. Gregory, R. A., H. J. Tracy, J. I. Harris, M. J. Runswick, S. Moore, G. W. Kenner, and R. Ramage. 1979. Minigastrin: corrected structure and synthesis. Hoppe-Seyler's Z. Physiol. Chem. 360:73-80.

17. Petersen, B., and J. F. Rehfeld. 1980. The $\mathrm{NH}_{2}$-terminal tridecapeptide fragment of gastrin-17 in serum from duodenal ulcer patients. Scand. J. Gastroent. 15:29-31.

18. Gregory, R. A. 1974. The gastrointestinal hormones: a review of recent advances. J. Physiol. 241:1-32.

19. Gregory, R. A. 1979. Some recent aspects of the structure of gastrin and gastrin-like forms and fragments in gut and brain. In Gastrins and the Vagus. J. F. Rehfeld and E. Amdrup, editors. Academic Press, London. 47-55.

20. Carter, D. C., I. L. Taylor, J. Elashoff, and M. I. Grossman. 1979. Reappraisal of the secretory potency and disappearance rate of pure human minigastrin. Gut. 20:705-708.

21. Petersen, B., J. Christiansen, and J. F. Rehfeld. 1983. The Nterminal tridecapeptide fragment of gastrin 17 inhibits gastric acid secretion. Reg. Peptides. 7:323-334.

22. Pauwels, S., G. J. Dockray, R. Walker, and S. Marcus. 1984. $\mathrm{N}$-terminal tryptic fragment of big gastrin: metabolism and failure to influence G-17 evoked acid secretion in man. Gastroenterology. 86: 86-92. 